\title{
KINETIC MODELLING OF GAS GENERATED FROM ANAEROBIC FERMENTATION OF KITCHEN WASTE WITH MICROAEROBIC PRETREATMENT
}

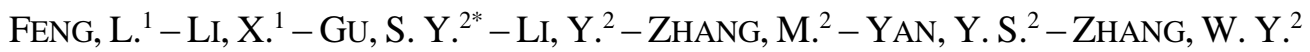 \\ ${ }^{1}$ Liaoning Province Clean Energy Key Laboratory, Shenyang Aerospace University, Shenyang \\ Daoyi Street 37, Shenyang 110136, China \\ ${ }^{2}$ Shenyang Agricultural University, Shenyang Dongling Street 120, Shenyang 110866, China \\ *Corresponding author \\ e-mail: syndgsy@126.com; phone: +86-137-0985-0916
}

(Received $1^{\text {st }}$ Mar 2019; accepted $21^{\text {st }}$ May 2019)

\begin{abstract}
Anaerobic fermentation is one of the effective ways to achieve the harmless, resource-reducing and reducing of kitchen waste. In this paper, the oxygen content under initial conditions in the anaerobic fermentation process of kitchen waste was changed by experiment (for micro-oxygen pretreatment). It was verified that trace oxygen can optimize the anaerobic fermentation system and increase the rate of anaerobic fermentation. Through the study of the gas production characteristics of the micro-oxygen experiment group, by using the Logistic model and the modified Gompertz model, the $\mathrm{R}^{2}$ is above 0.99 , and the fitting effect is better. The first-order hydrolysis model was combined with different particle reaction kinetic models to obtain a modified first-order gas production model. The results show that the air intake is suitable for the cylindrical particle model. The corresponding $\mathrm{R}^{2}$ and $\mathrm{k}$ values for the air intake from $0 \mathrm{ml}$ to $20 \mathrm{ml}$ are: $\ln \left(\mathrm{y}_{\mathrm{m}}\right)+\ln (\mathrm{k})=0.98298, \mathrm{k}=0.04339 ; \ln \left(\mathrm{y}_{\mathrm{m}}\right)+\ln (\mathrm{k})=0.96149, \mathrm{k}=0.04706 ; \ln \left(\mathrm{y}_{\mathrm{m}}\right)+\ln (\mathrm{k})=0.98219$, $\mathrm{k}=0.04611 ; \ln \left(\mathrm{y}_{\mathrm{m}}\right)+\ln (\mathrm{k})=0.94356, \mathrm{k}=0.05039 ; \mathrm{R}^{2}=0.9327, \mathrm{k}=0.05149 ;$ the fitting effect is better. The population growth model and the modified primary gas production model can better describe the effect of oxygen content change on anaerobic fermentation gas production, and have important significance for the application of anaerobic fermentation in actual production and life processes.
\end{abstract}

Keywords: kitchen waste, microaerobic pretreatment, kinetic analysis, population model, modified firstorder gas-generation model

\section{Introduction}

Waste and pollution of kitchen waste is a worldwide economic and environmental problem. Per capita production of $95-115 \mathrm{~kg}$ of kitchen waste per year in Europe and North America exceeds one third of the total food produced in the region. China is due to population base. Larger, with the rapid increase in the amount of organic waste and municipal sludge produced in recent years, the amount of kitchen waste produced in China reached 95 million tons in 2015, and the average daily waster output was as high as 260,000 tons per day The per capita annual output is $73 \mathrm{~kg}$ (Zeng, 2017). One of the effective ways to treat kitchen waste by anaerobic digestion has many advantages: Anaerobic digestion of food waste has many advantages: the generated biogas is an alternative to fossil fuels and thus can ease the energy shortage problem; processed biogas can be used as organic fertilizer, enabling a resource utilization of food waste; the process only produces a little amount of secondary pollution. Therefore, anaerobic digestion of food waste is in line with the "reduction, resource recovery, non-toxic" principle for waste treatment. Overall, this waste treatment process is not only environment-friendly, but also can promote a sustainable economic development (Melikoglu and Webb, 2013). 
In the current research background, the three models commonly used in the study of organic matter hydrolysis kinetics model are the first-order hydrolysis model, the Monod model and the Contois model. Huang et al. (2017) used kitchen waste and activated sludge as substrates for anaerobic fermentation, and used the first-order kinetic model to fit the methane production and predict the late methane production, The predicted value and the actual measured value have less error; Sun et al. (2016) carried out anaerobic digestion experiments using cow dung and corn stover as raw materials, and simulated the Gompertz model. The $\mathrm{R}^{2}$ of the fitting equation of cow dung and corn stover were 0.983 and 0.991, and the predicted and experimental measured values were $12.3 \%$ and $1.7 \%$. Miao et al. (2014) and Syai-churrozi et al. (2013) also fitted anaerobic digestion methane production of cyanobacteria, pig manure and distiller's grains based on the revised Gompertz model, providing a scientific assessment method for predicting the methanogenic potential of various raw materials in the future, but the revised Gompertz model can only characterize the gas production potential of the fermentation substrate, and it is difficult to reflect the influence of influencing factors such as organic load and hydraulic retention time on the gas production rate. Liu et al. (2017) established the PSOSVM anaerobic digestion gas production prediction model by controlling the temperature, $\mathrm{pH}$, oxidation-reduction potential, and influent organic load as the input, and the gas production as the output, which improved the accuracy of the model. Jurado et al. (2016) first pretreated the pig manure by aqueous ammonia soaking method, and based on the ADM1 kinetic model, the anaerobic fermentation of the pretreated pig manure was fitted. The results show that the ADM1 model has poor prediction ability for anaerobic fermentation process after aqueous ammonia soaking treatment. The reason may be that the hydrolysis rate of the treated pig manure is increased, and the hydrolysis constant needs to be revised to meet the requirements. Lauwers et al. (2013) and other studies have shown that the ADM1 model is suitable for a single matrix substrate, the practical application process is more complicated, and the ADM1 model is more difficult to apply.

As a key factor in the anaerobic fermentation process, oxygen concentration has a significant impact on the generation of biogas. By changing the concentration of oxygen, the activity of the microflora in the system can be manipulated. Thus, increasing the biological activity of aerobic microorganisms and facultative anaerobic microorganisms in the anaerobic fermentation process represents a means for regulating the gas-generation in the system. However, there is currently no systematic kinetic model established for the anaerobic fermentation process of kitchen waste with microaerobic pretreatment, and both the kinetic and mechanistic analyses are lacking (Mata-Alvarez et al., 2000; ForsterCarneiro et al., 2008; Pavan et al., 2000). To this end, in this study, we established three models, namely, a population growth model, a modified Gompertz model and a modified first-order gas-generation model. With them, we explored the impact of oxygen concentration on the microaerobic pretreatment process and system gas-generation. Based on our data, we also provided suggestions for the subsequent industrialization of the process.

\section{Materials and methods}

\section{Experimental materials}

The raw materials used in this experiment mainly include kitchen waste and inoculated sludge, which were collected from the Southern District Canteen of 
Shenyang Aerospace University and the sewage treatment plant in north Shenyang City (Liaoning province), respectively. First, mix the different kitchen wastes (including taro, vegetables, meat, eggs and other proteins). Remove other materials such as bones and paper scraps from the kitchen waste, stir them with a blender, and store them in cold storage; The inoculated mud was taken from the anaerobic digestion sludge of the sewage treatment plant in the northern part of Shenyang City, Liaoning Province.

\section{Experimental methods}

A wide-mouth reagent bottle $(1 \mathrm{~L})$ was used as the anaerobic fermentation tank (Fig. 1). The raw material for anaerobic fermentation was kitchen waste (simulation), and a certain amount of inoculated sludge was added to the anaerobic digestion tank. Anaerobic digestion was carried out in a water bath at $37^{\circ} \mathrm{C}$. Five parallel groups were set up. Group 1 was used as a control and it was carried out as a standard anaerobic fermentation. Groups 2-5 were experimental groups, and $5 \mathrm{ml}, 10 \mathrm{ml}, 15 \mathrm{ml}$, and $20 \mathrm{ml}$ of air were respectively inflated to create different microaerobic conditions. The biogas generation in each group was measured once a day, and the total amount of biogas generation in each group was also calculated. The experimental period is 50 days, of which 1-10 days is the adaptation period. At this time, the microorganisms are in the adaptation stage, also called the start-up stage, mainly by hydrolyzing the fermenting bacteria group to act on starch and cellulose. Hydrogen-producing bacterial bacteria convert monosaccharides into volatile fatty acids (VFAs), $\mathrm{H}_{2}$ and $\mathrm{CO}_{2} .31-50$ days is the deceleration period and the decay period. Since a large amount of organic matter in chicken manure and straw is consumed, the microorganisms enter the endogenous respiration stage and begin to sleep or die.

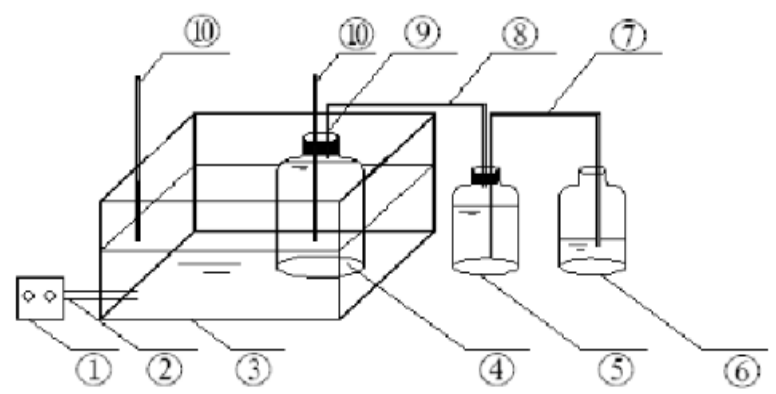

Figure 1. Experimental set-up. 1 - Controller, 2 - Heater, 3 - Water bath, 4 - Sample reactor, 5 - Gas cylinders, 6 - Water collection bottle, 7 - Outlet pipe, 8 - Airway, 9 - Detection tube, 10 thermometer

\section{Model establishment}

\section{A kinetics model for anaerobic fermentation}

The hydrolysis kinetics model is mainly classified according to the type of organic matter and the hydrolysis process. There are three major categories: the ones based on organic matter concentration, the ones based on organic matter composition and the ones based on organic surface area. The most commonly used organic-concentrationsbased hydrolysis kinetic models are the Monod model, the Contois model, and the firstorder hydrolysis model. 
The Monod model was proposed by the founder of modern cell growth kinetics, Monod, in 1942. This model describes the relationship between the limiting substrate concentration of cells and their growth rate during the equilibrium and log phase of the microbial growth.

The Contois model was proposed about 20 years later than the Monod model. It describes the growth of microorganisms over time. The Contois model was first applied to the hydrolysis process of the soluble organic matters in aerobic activated sludge, and later developed also for the anaerobic fermentation process of organic particulates. The Contois model is a modified Monod model, which assumes that saturation constant is proportional to the initial concentration of the substrate. However, this model also has disadvantages: for example, it does not consider the influence of temperature on the rate of hydrolysis (Rao and Singh, 2004; Fang and Yu, 2002; Song et al., 2004).

First-order hydrolysis model is the simplest model for the hydrolysis of organic matters. It assumes that the concentration of unhydrolyzed organic matter is proportional to the hydrolysis rate; thus, this model is not suitable for the lag phase. By comparing the actual anaerobic fermentation process with the simulation, First-order hydrolysis model is considered as the model of choice for simulating the hydrolysis of organic particulates (Rao and Singh, 2004). It can be improved by introducing the concept of specific surface area of hydrolyzed particles into the model (Song et al., 2004). Although the hydrolysis characteristics of the specific components in the hydrolysis model are not particularly clear because of the different compositions of organic particulates, the kinetic model regarding the mixture as a hydrolyzed whole, compared to the conventional one, undoubtedly provides some clues for future studies.

\section{Anaerobic fermentation kinetics models for the SBR system}

\section{Population growth model}

The Logistic equation is:

$$
P=\frac{P_{\max }}{1+\exp \left[\frac{4 R_{\max }(\lambda-t)}{p_{\max }}+2\right]}
$$

where $\mathrm{P}$ is the cumulative amount of methane generation $(\mathrm{ml} / \mathrm{gVS})$ at time point $\mathrm{t}$; Pmax is the potential maximum methane generation ( $\mathrm{ml} / \mathrm{gVS})$; Rmax is the maximum methanogenic rate $(\mathrm{ml} / \mathrm{gVS} / \mathrm{d})$; $t$ is the reaction time; and $\lambda$ is the delay time $(\mathrm{d})$.

The modified Gompertz equation is:

$$
M=P \times \exp \left\{-\exp \left[\frac{R_{m} \times e}{P}(\lambda-t)+1\right]\right\}
$$

where $\mathrm{M}$ is the accumulative amount of methane generation at time point $\mathrm{t}(\mathrm{ml} / \mathrm{gVS}) ; \mathrm{P}$ is the potential maximum methane generation $(\mathrm{ml} / \mathrm{gVS}) ; \mathrm{Rm}$ is the maximum methanogenic rate $(\mathrm{ml} / \mathrm{g} / \mathrm{VS} / \mathrm{d})$; $\mathrm{t}$ is the reaction time; and $\lambda$ is the delay time $(\mathrm{d})$.

It can be seen from these two equations that the P, Pmax, and Rmax in the Logistic equation represent the same as the kinetic parameters, $\mathrm{M}, \mathrm{P}$ and $\mathrm{Rm}$ in the modified Gompertz equation. In this study, we performed nonlinear regression analysis (a 
function incorporated in the origin 8.0 software) of the kinetic parameters in the Logistic equation and the modified Gompertz equation.

\section{First-order gas-generation model}

Because of the proportional relationship between degradable organic matter and methane generation derived the first-order gas-generation model based on previous studies (Vavilin et al., 2008):

$$
\frac{1}{t} \ln \left(\frac{d y_{t}}{d_{t}}\right)=\frac{1}{t}\left(\ln \left(y_{m}\right)+\ln k\right)-k
$$

where $\mathrm{y}_{\mathrm{m}}$ is the theoretical methane generation per unit degradable organic matter $(\mathrm{ml} / \mathrm{gVS}) ; \mathrm{y}_{\mathrm{t}}$ is the methane generation per unit degradable organic matter at time point $\mathrm{t}$ $(\mathrm{ml} / \mathrm{gVS}) ; \mathrm{t}$ is the reaction time $(\mathrm{d}) ; \mathrm{k}$ is the hydrolysis constant $\left(\mathrm{d}^{-1}\right)$.

By combining Equations 2 and 3, we obtained the $\operatorname{Ln}\left(\mathrm{y}_{\mathrm{m}}\right)+\ln (\mathrm{k})$ and the k value of the corresponding organic matter, which were used for the following analysis.

\section{Modified first-order gas-generation model}

The modified first-order gas-generation model is based on the modified first-order hydrolysis model. Modified first-order hydrolysis models include pellet particle model, cylindrical particle model, and spherical particle model. The conclusions are shown in Table 1.

Table 1. The conclusions of three hydrolysis models

\begin{tabular}{c|c|c}
\hline Pellet particle model & Cylindrical particle model & Spherical particle model \\
\hline$c=c_{0} e^{-k t}$ & $c=c_{0}\left(\frac{1}{2} k t+1\right)^{-2}$ & $c=c_{0}\left(\frac{2}{3} k t+1\right)^{\frac{3}{2}}$ \\
$\frac{d c}{d t}=-k c$ & $\frac{d c}{d t}=-k \frac{c^{\frac{3}{2}}}{c_{0}^{\frac{1}{2}}}$ & $\frac{d c}{d t}=-k \frac{c^{\frac{5}{3}}}{c_{0}^{\frac{2}{3}}}$ \\
\hline
\end{tabular}

For our modified first-order gas-generation model, we referred to the first-order hydrolysis model, and used cumulative methane generation to indicate the degree of hydrolysis of the substrate. Considering the proportional relationship between the gas generation rate of anaerobic fermentation and the degradation rate of organic matter, and the initial generation rate in the SBR system is 0, we have:

$$
G=\frac{\alpha}{c_{0}}\left(c_{0}-c\right)
$$

Putting the conclusions shown in Table 1 into Equation 4, we have: 


$$
\begin{gathered}
G=\alpha\left(1-e^{-k t}\right) \\
G=\alpha\left[1-\left(\frac{1}{2} k t+1\right)\right] \\
G=\alpha\left[1-\left(\frac{2}{3} k t+1\right)^{\frac{3}{2}}\right]
\end{gathered}
$$

where $\mathrm{t}$ is the reaction time (d); $\mathrm{k}$ is the Hydrolysis constant $\left(\mathrm{d}^{-1}\right)$; $\mathrm{c}$ is the concentration of volatile solid matters ( $\mathrm{gVS}$ ); $\mathrm{c}_{0}$ is the initial concentration of the volatile solid matters ( $\mathrm{gVS}$ ); $\mathrm{G}$ is the cumulative biogas generation ( $\mathrm{mL} / \mathrm{gVS}$ ); $\alpha$ is the conversion rate of the volatile solid matters (mL/gVS). Equations 5, 6 and 7 correspond to pellet particle, cylindrical particle, and spherical particle models, respectively. Using origin 8.0, we did a linear regression analysis to compare the hydrolysis constants of these models.

\section{Experimental result analysis and model verification}

\section{Statistical analysis of experimental results}

Through the statistics of the cumulative gas production of each group of experiments, it can be seen that the gas production of the system is lower under different microoxygen concentration conditions in the initial stage of the experiment. This is because the anaerobic digestion of kitchen waste is in the adaptation stage at the beginning of the experiment, and the activity of methanogens and other strains in the system is low; as the experiment progresses, the daily gas production begins to rise gradually. Each system of different oxygen concentrations reached the first peak around day 10, $511 \mathrm{ml}$ $(5 \mathrm{ml}), 490(10 \mathrm{ml}), 607(15 \mathrm{ml}), 586 \mathrm{ml}(20 \mathrm{ml}), 498.5(0 \mathrm{ml})$. Since a large amount of substrate is decomposed into small molecular organic substances and cannot be consumed in time, a large amount of organic acid accumulation changes the neutral environment suitable for the growth of methanogens, thereby inhibiting the activity of methanogens, resulting in a decrease in daily gas production. As the experiment progressed, the methanogens passed the inhibition phase and the gas production gradually recovered. The system of different oxygen concentrations reached the second peak of gas production around the 20th day, and then the gas production between different systems will also fluctuate slightly until the end of the experiment.

In the meantime, the gas production conditions of different oxygen concentration systems show different rules. Each system reached the first peak of gas production around the tenth day. At the beginning of the experiment, the daily gas production of the $20 \mathrm{ml}$ experimental group was up to $586 \mathrm{ml}$, and the daily gas production of the $0 \mathrm{ml}$ blank experimental group was only $314 \mathrm{ml}$. Therefore, the gas production rate of the $20 \mathrm{ml}$ micro-oxygen test group at the initial stage of the experiment was higher than that of the $0 \mathrm{ml}$ blank test group. This is because the presence of trace oxygen makes the system a small amount of organic matter consumed by aerobic bacteria in the initial stage of fermentation, so that the accumulation of organic acids is less, and the inhibitory effect on methanogens in the system is reduced. According to the statistical analysis of the data, it can be seen that since the initial materials are the same, the 
cumulative gas production of each group is about $11.5 \mathrm{~L}$. However, the experimental period of the micro-oxygen test group was shorter than that of the control group, and the reaction rate was faster as the oxygen content increased. The $0 \mathrm{ml}$ control group entered the late stage of the experiment at about 40 days, and the $20 \mathrm{ml}$ group entered the later stage of the experiment when it was about 25 days old, and the reaction rate increased by $37.5 \%$. The experimental results show that micro-oxygen pretreatment can accelerate the reaction rate of anaerobic fermentation, which is of great significance to the actual production and life.

\section{Discussion of the Logistic equation and the modified Gompertz equation}

During the experiment, the other influencing factors (Temperature, $\mathrm{pH}$, Organic matter concentration, Mass transfer efficiency) were constant, and the change in the gas-generation was achieved by manipulating the concentration of the air that was inflated. The data were input into the original 8.0 software for nonlinear fitting. The results were shown in Figure 2. It can be seen from Table 2 that the fitting based on the Logistic equation gave high $\mathrm{R}^{2}$ values (all >0.99), indicating a well-fitting effect of the equation; thus, the anaerobic fermentation process can be accurately simulated. On the other hand, the Gompertz equation also performed very well, with only one $\mathrm{R}^{2}$ value below 0.99 ( $\mathrm{R}^{2}$ of the $5 \mathrm{ml}$ data), and it therefore also can be employed for the fermentation with microaerobic pretreatment (Table 3). Nevertheless, a detailed comparison between these two equations suggests that the Logistic equation performs slightly better (Duan et al., 2016).

Table 2. The fitting parameters of the Logistic equation

\begin{tabular}{c|c|c|c|c|c}
\hline Microaerobic level & $\mathbf{P}_{\max }(\mathbf{m l} / \mathbf{g V S})$ & $\mathbf{R}_{\max }(\mathbf{m l} / \mathbf{g V S})$ & $\boldsymbol{\lambda}(\mathbf{b})$ & $\mathbf{R}^{\mathbf{2}}$ & $\mathbf{R M S E}$ \\
\hline $0 \mathrm{ml}$ & 163.0659 & 4.9061 & 6.6926 & 0.9987 & 2.7806 \\
$5 \mathrm{ml}$ & 155.7169 & 5.5464 & 7.0825 & 0.9966 & 5.3478 \\
$10 \mathrm{ml}$ & 149.8337 & 4.8603 & 6.0728 & 0.9961 & 2.9435 \\
$15 \mathrm{ml}$ & 172.0383 & 6.1555 & 4.2376 & 0.9982 & 2.2739 \\
$20 \mathrm{ml}$ & 177.7048 & 7.3598 & 5.9396 & 0.9981 & 5.7349 \\
\hline
\end{tabular}

Table 3. The fitting parameters of the Gompertz equation

\begin{tabular}{c|c|c|c|c|c}
\hline Microaerobic level & $\mathbf{P}_{\max }(\mathbf{m l} / \mathbf{g V S})$ & $\mathbf{R}_{\max }(\mathbf{m l} / \mathbf{g V S})$ & $\boldsymbol{\lambda}(\mathbf{b})$ & $\mathbf{R}^{\mathbf{2}}$ & $\mathbf{R M S E}$ \\
\hline $0 \mathrm{ml}$ & 192.9103 & 4.4659 & 4.8080 & 0.9966 & 1.7100 \\
$5 \mathrm{ml}$ & 173.8075 & 5.0624 & 5.3332 & 0.9881 & 2.8803 \\
$10 \mathrm{ml}$ & 167.6019 & 4.5520 & 4.6021 & 0.9974 & 2.3736 \\
$15 \mathrm{ml}$ & 186.169 & 5.7861 & 2.8244 & 0.9917 & 4.7257 \\
$20 \mathrm{ml}$ & 188.7640 & 6.9479 & 4.6672 & 0.9902 & 2.5224 \\
\hline
\end{tabular}

As indicated by the $\mathrm{R}^{2}$ values, the Gompertz equation had a better fitting effect for the $5 \mathrm{ml}$ group and $10 \mathrm{ml}$ group, whereas the Logistic equation had a better performance for $0 \mathrm{ml}, 15 \mathrm{ml}$ and $20 \mathrm{ml}$ groups. Meanwhile, we can also conclude that under good fitting conditions, $20 \mathrm{ml}$ of air intake had the highest gas-generation potential. This shows that the addition of a proper amount of oxygen can increase the activity of 
facultative anaerobic bacteria in the system. These "active" bacteria subsequently promote the anaerobic digestion process, increasing the degradation efficiency of the substrate and improving the gas production potential of the whole system (Pontes and Pinto, 2006; Garcia-Ochoa et al., 1999).

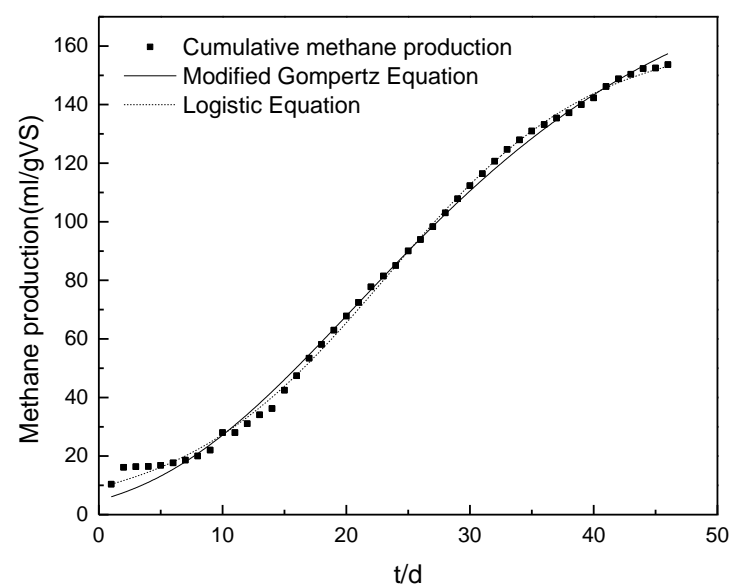

a Pass $0 \mathrm{ml}$ air fitting curve

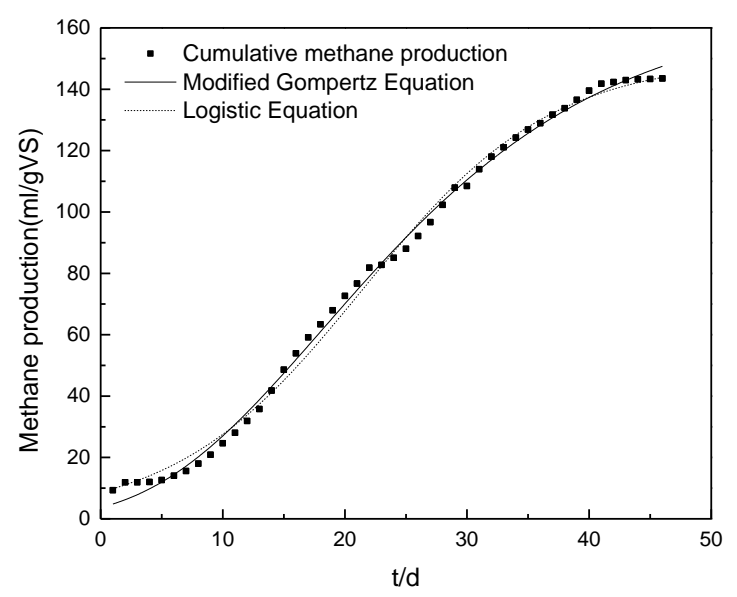

c Pass $10 \mathrm{ml}$ air fitting curve

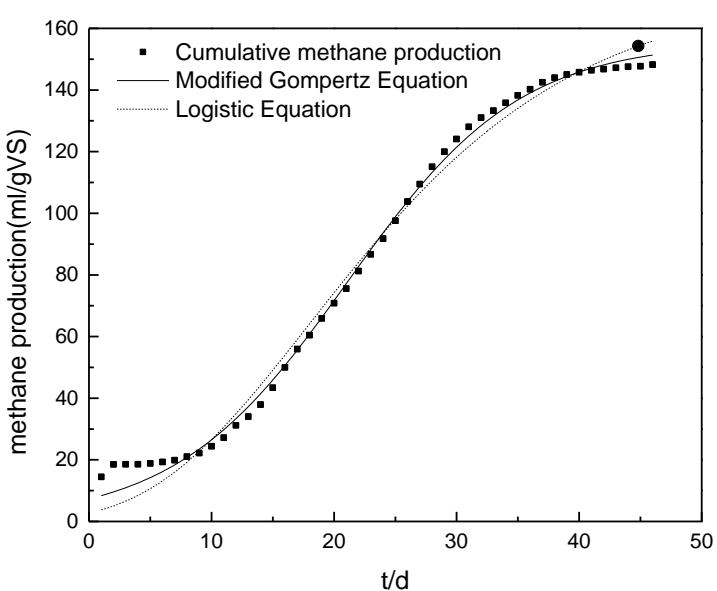

b Pass $5 \mathrm{ml}$ air fitting curve

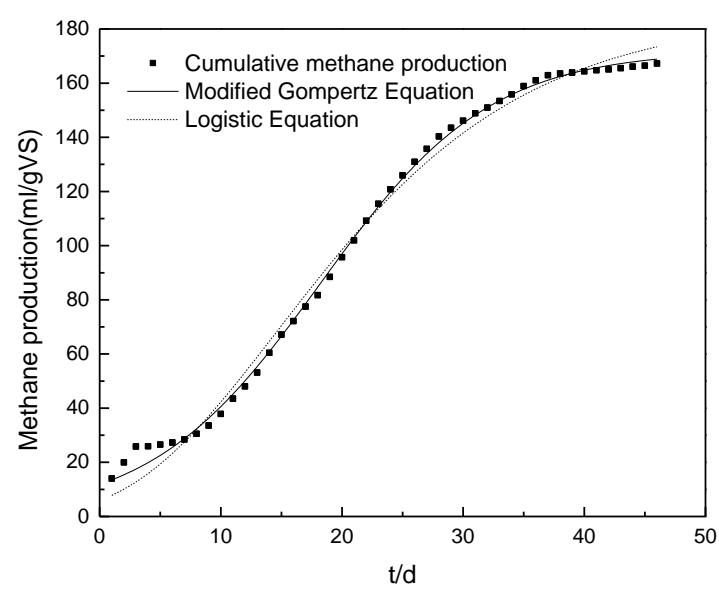

d Pass $15 \mathrm{ml}$ air fitting curve

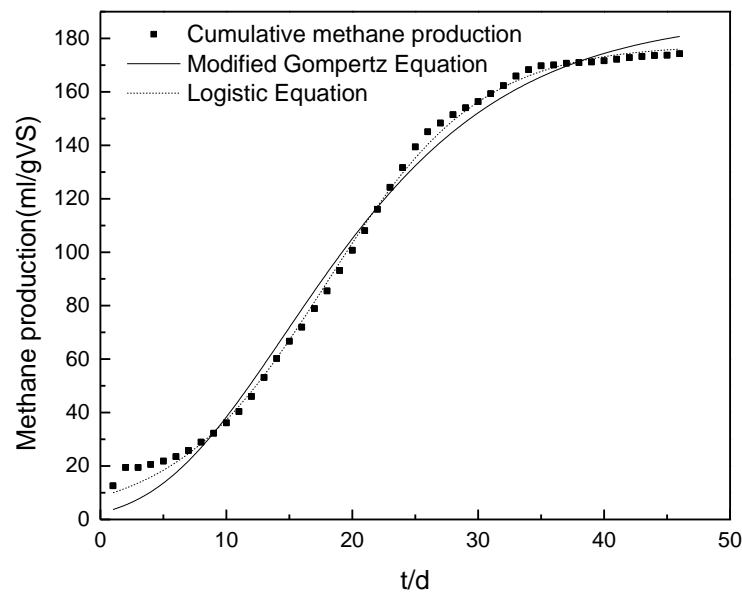

e Pass $20 \mathrm{ml}$ air fitting curve

Figure 2. Comparison of fitted function graphs of Logistic and Gompertz equations under different air concentrations 


\section{Analysis of the first-order gas-generation kinetics model}

Using the equation of the first-order gas-generation model, the fitting diagrams were shown in Figure 3. Except for $0 \mathrm{ml}$ and $10 \mathrm{ml}$ groups, the $\mathrm{R}^{2}$ values were all greater than 0.97 (i.e., other $\mathrm{R}^{2}$ values were below 0.97 ), indicating it was not able to simulate the experimental data.

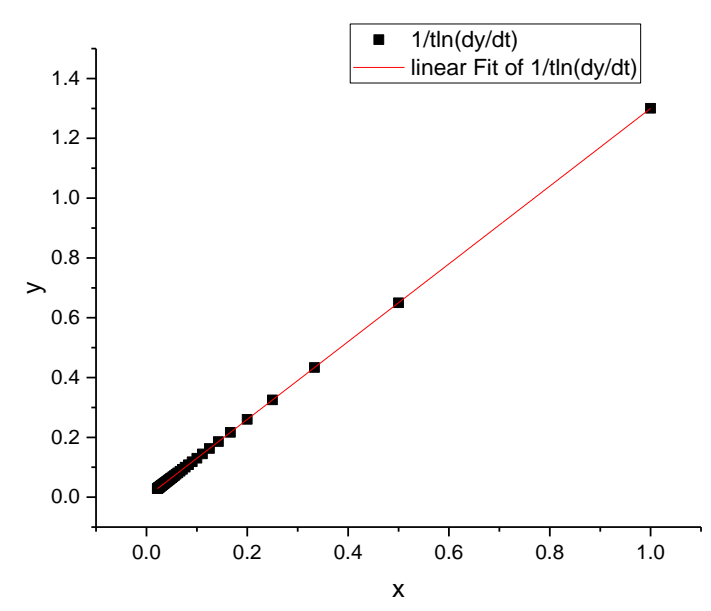

a Pass $0 \mathrm{ml}$ air fitting curve

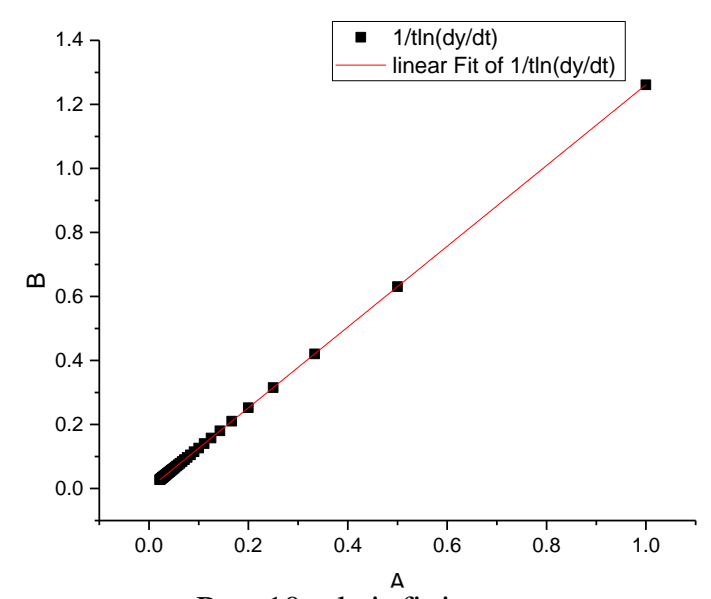

c Pass $10 \mathrm{ml}$ air fitting curve

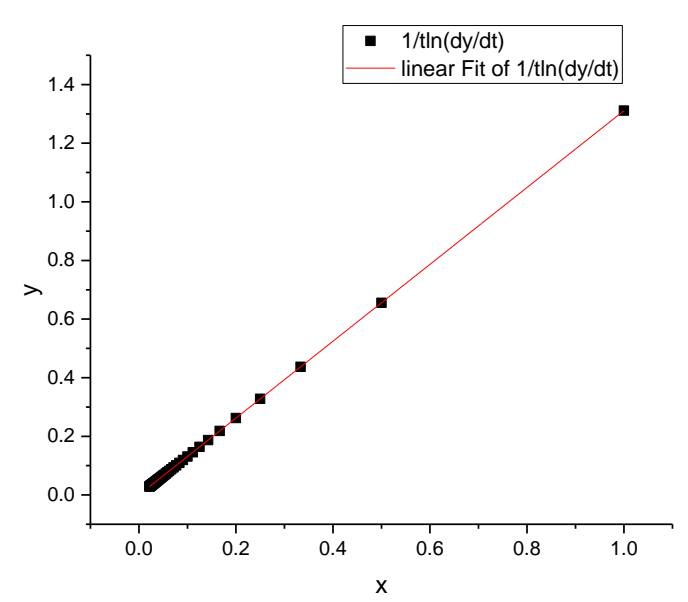

b Pass $5 \mathrm{ml}$ air fitting curve

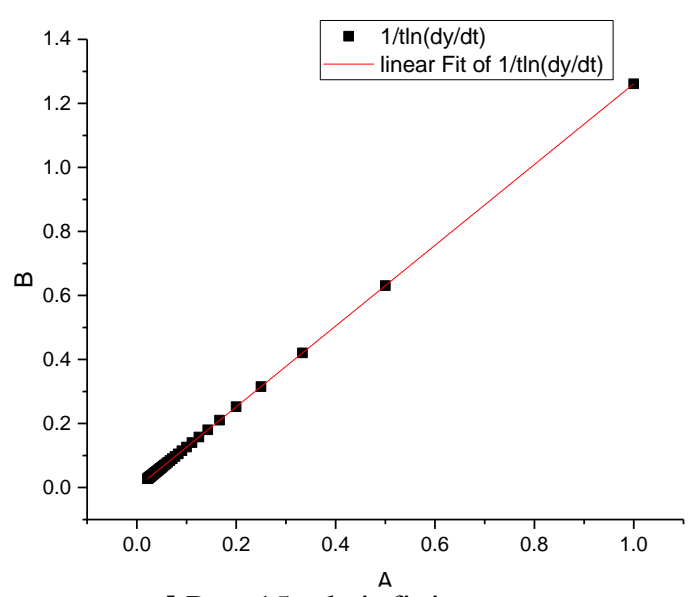

d Pass $15 \mathrm{ml}$ air fitting curve

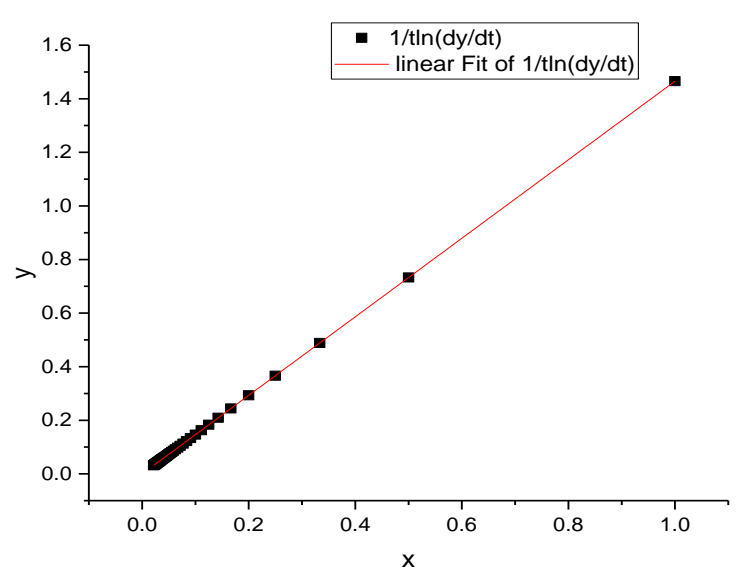

e Pass $20 \mathrm{ml}$ air fitting curve

Figure 3. First-order gas-generation fitting diagrams of each experimental group 
The $\mathrm{k}$ represents the degradation rate of the degradable portion of the substrate: the lower the value of $\mathrm{k}$, the slower the reaction rate; otherwise, the faster the reaction. It can be concluded from Table 4 that the $\mathrm{k}$ value of the $0 \mathrm{ml}$ group is the highest $(\mathrm{k}=0.00012)$, indicating that the reaction of this group was the fastest. The second highest $\mathrm{k}$ value (0.000051), which is only slightly lower, was found in the $5 \mathrm{ml}$ group. The $20 \mathrm{ml}$ group had the lowest reaction rate $(\mathrm{k}=0.000010)$. These data also showed that in the $0 \mathrm{ml}$ group, gas-generation peaked at the early stage of the experiment.

Table 4. Parameters of the first-order gas-generation model for each group

\begin{tabular}{c|c|c|c}
\hline \multirow{2}{*}{ Microaerobic level } & \multicolumn{3}{|c}{ Parameters } \\
\cline { 2 - 4 } & $\ln \left(\mathbf{y}_{\mathbf{m}}\right)+\ln (\mathbf{k})$ & $\mathbf{k}$ & $\mathbf{R}^{\mathbf{2}}$ \\
\hline $0 \mathrm{ml}$ & 1.30019 & 0.00012 & 0.9843 \\
$5 \mathrm{ml}$ & 1.31103 & 0.000052 & 0.9608 \\
$10 \mathrm{ml}$ & 1.2613 & 0.000026 & 0.9824 \\
$15 \mathrm{ml}$ & 1.38128 & 0.000051 & 0.95225 \\
$20 \mathrm{ml}$ & 1.46557 & 0.000010 & 0.93532 \\
\hline
\end{tabular}

$\mathrm{y}_{\mathrm{m}}$ represents the amount of biogas generated by the reaction, and $\mathrm{k}$ represents the speed of the reaction. Neither $\mathrm{y}_{\mathrm{m}}$ nor $\mathrm{k}$ along can fully characterize the gas -generation from the kitchen waste. However, $\ln \left(\mathrm{y}_{\mathrm{m}}\right)+\ln (\mathrm{k})$, a parameter combining $\mathrm{y}_{\mathrm{m}}$ and $\mathrm{k}$, can indicate the availability of the degradable part of the substrate. Therefore, it can be considered as an indicator of the methanogenesis characteristics, which include the speed of gas-generation and the amount of gas-generation. Thus, the larger this value, the better the gas-generation characteristics of the corresponding experimental group (Linke, 2006).

While the value of $\mathrm{k}$ obtained in our study can directly indicate the speed of reaction in each experimental group, to have a more comprehensive comparison, we also checked the value of $\ln _{m}+\operatorname{lnk}$ for each group, which can directly indicate the methanogenesis characteristics. In our data, $20 \mathrm{ml}$ group had the highest $\ln \mathrm{y}_{\mathrm{m}}+\operatorname{lnk}$ value (1.46557), suggesting it is of relatively optimal methanogenic characteristics in comparison with the other four groups. This is consistent with the conclusions drawn by using the Logistic equation. For other groups, from high to low, their lny $y_{m}+\operatorname{lnk}$ values were $1.38128(15 \mathrm{ml}), 1.31103(5 \mathrm{ml}), 1.30019(0 \mathrm{ml})$, and $1.2613(10 \mathrm{ml})$. These data clearly demonstrate that the addition of micro-oxygen, if not destroying the microaerobic environment, can promote the degradation of the substrate and increase the methane yield.

\section{Analysis of the modified first-order gas-generation model}

Using the models described above, we revealed that the $5 \mathrm{ml}$ experimental group had the longest delay time ( $8 \mathrm{~d}$ ), followed by the $0 \mathrm{ml}$ group ( 7 days) and the $20 \mathrm{ml}$ group (6 days). The groups with the shortest delay time were the $10 \mathrm{ml}$ and $15 \mathrm{ml}$ groups (both 5 days). As mentioned previously, the modified first-order gas-generation model was derived from the modified first-order hydrolysis model, and the first-order hydrolysis model does not include the lag phase when estimating the hydrolysis constant $\mathrm{k}$. Consequentially, for the anaerobic fermentation process with a significant lag phase, the estimation of the hydrolysis constant must exclude the lag period. The $\mathrm{k}$ values are 
listed in Table 5. Our data suggest that cylindrical particle model is suitable for every oxygen concentration, followed by the pellet particle model, and the last is the spherical particle model. The hydrolysis constants of the cylindrical particle model for each concentration (from $0 \mathrm{ml}$ to $20 \mathrm{ml}$ ) were $0.04339,0.04706,0.04611,0.05039$ and 0.05149 , respectively.

Table 5. Parameters of the modified first-order gas-generation model for each group

\begin{tabular}{c|c|c|c|c}
\hline $\begin{array}{c}\text { Microaerobic } \\
\text { level }\end{array}$ & Model & $\begin{array}{c}\text { Pellet particle } \\
\text { model }\end{array}$ & $\begin{array}{c}\text { Cylindrical } \\
\text { particle model }\end{array}$ & $\begin{array}{c}\text { Spherical particle } \\
\text { model }\end{array}$ \\
\hline \multirow{2}{*}{$0 \mathrm{ml}$} & $\mathrm{R}^{2}$ & 0.8841 & 0.9830 & 0.7987 \\
& $\mathrm{~K}(1 / \mathrm{d})$ & 0.0350 & 0.0434 & 0.0462 \\
\hline \multirow{2}{*}{$5 \mathrm{ml}$} & $\mathrm{R}^{2}$ & 0.8641 & 0.9615 & 0.7692 \\
& $\mathrm{~K}(1 / \mathrm{d})$ & 0.0403 & 0.0471 & 0.0548 \\
\hline \multirow{2}{*}{$10 \mathrm{ml}$} & $\mathrm{R}^{2}$ & 0.8911 & 0.9822 & 0.8008 \\
& $\mathrm{~K}(1 / \mathrm{d})$ & 0.0391 & 0.0461 & 0.0528 \\
\hline \multirow{2}{*}{$15 \mathrm{ml}$} & $\mathrm{R}^{2}$ & 0.9035 & 0.9436 & 0.8046 \\
& $\mathrm{~K}(1 / \mathrm{d})$ & 0.0478 & 0.0504 & 0.0680 \\
\hline \multirow{2}{*}{$20 \mathrm{ml}$} & $\mathrm{R}^{2}$ & 0.8810 & 0.9327 & 0.7778 \\
& $\mathrm{~K}(1 / \mathrm{d})$ & 0.0493 & 0.0515 & 0.0701 \\
\hline
\end{tabular}

Based on the above analysis, including the ones for the lag phase and the modified first-order gas-generation model, the complete periodic equations can be obtained by inputting the value (from Population growth model) and the $\mathrm{k}$ value (from first-order gas-generation model) into the equation. For each group, they are:

$$
\begin{gathered}
G_{1}=\left\{\begin{array}{l}
-0.0351 \mathrm{t}^{4}+0.7142 t^{3}-5.0891 t^{2}+15.3286 t, 1 \leq t \leq 7 \\
163.0659\left[1-\left(\frac{1}{2} \times 0.0434 t+1\right)\right], 8 \leq t \leq 46
\end{array}\right. \\
G_{2}=\left\{\begin{array}{l}
0.0094 t^{5}-0.2385 t^{4}+2.3185 t^{3}-10.6587 t^{2}+23.0191 t, 1 \leq t \leq 8 \\
155.7169\left[1-\left(\frac{1}{2} \times 0.0471 t+1\right)\right], 9 \leq t \leq 46
\end{array}\right. \\
G_{3}=\left\{\begin{array}{l}
-0.0761 t^{4}+1.1732 t^{3}-6.3810 t^{2}+14.6148 t, 1 \leq t \leq 5 \\
149.8337\left[1-\left(\frac{1}{2} \times 0.0461 t+1\right)\right], 6 \leq t \leq 46
\end{array}\right. \\
G_{4}=\left\{\begin{array}{l}
0.2469 t^{3}-3.4825 t^{2}+16.5419 t, 1 \leq t \leq 5 \\
172.0383\left[1-\left(\frac{1}{2} \times 0.0504 t+1\right)\right], 6 \leq t \leq 46
\end{array}\right. \\
G_{5}=\left\{\begin{array}{l}
0.4875 t^{3}-5.072 t^{2}+17.5546 t, 1 \leq t \leq 6 \\
177.7048\left[1-\left(\frac{1}{2} \times 0.0515 t+1\right)\right], 7 \leq t \leq 46
\end{array}\right.
\end{gathered}
$$


Notably, this model is a modified model, which takes the lag phrase into consideration, thus better describing the individual stages of the anaerobic fermentation process. We anticipate that our analysis may guide the development of microaerobic pretreatment process and provides a theoretical basis for the kinetics analysis of sequencing anaerobic fermentation.

\section{Conclusion}

- Three Kinetic models of anaerobic fermentation of kitchen waste with microaerobic pretreatment were established. Among them, the Logistic model and the modified Gompertz model could better simulate the process since most of the $\mathrm{R}^{2}$ values were higher than 0.99 . Judging from the simulation results, the experimental group in which $20 \mathrm{ml}$ of air were inflated had the largest gas generation capacity.

- For the modified first-order gas-generation model, the cylindrical particle model was suitable for every air concentration. The corresponding $\ln \left(\mathrm{y}_{\mathrm{m}}\right)+\ln (\mathrm{k})$ values and $\mathrm{k}$ values for each group are: $0 \mathrm{ml}$ group, $\ln \left(\mathrm{y}_{\mathrm{m}}\right)+\ln (\mathrm{k})=0.98298, \mathrm{k}=0.04339 ; 5 \mathrm{ml}$ group, $\ln \left(\mathrm{y}_{\mathrm{m}}\right)+\ln (\mathrm{k})=0.96149$, $\mathrm{k}=0.04706 ; 15 \mathrm{ml}$ group, $\ln \left(\mathrm{y}_{\mathrm{m}}\right)+\ln (\mathrm{k})=0.98219, \mathrm{k}=0.04611 ; 20 \mathrm{ml}$ group, $\ln \left(\mathrm{y}_{\mathrm{m}}\right)+\ln (\mathrm{k})=0.94356, \mathrm{k}=0.05039 ; 20 \mathrm{ml}$ group, $\ln \left(\mathrm{y}_{\mathrm{m}}\right)+\ln (\mathrm{k})=0.9327$, $\mathrm{k}=0.05149$. It is worth noting these results were obtained from three simulations for each group. Every experimental group had a significant lag phrase. The longest lag phrase was $8 \mathrm{~d}$ for the $5 \mathrm{ml}$ experimental group, followed by the $0 \mathrm{ml}$ group ( 7 days) and the $20 \mathrm{ml}$ group ( 6 days). The groups with the shortest delay time were the $10 \mathrm{ml}$ and $15 \mathrm{ml}$ groups (both 5 days). Based on the modified first-order gas-generation model, the entire periodic equation taking the lag phrase into consideration was also generated.

Acknowledgements. This work was funded by Shenyang Science and Technology Plan Project: Study on biogas kinetics and process optimization of anaerobic fermentation of mixed raw materials (18-013-0-86).

\section{REFERENCES}

[1] Duan, X., Wang, X., Xie, J. et al. (2016): Effect of nonylphenol on volatile fatty acids accumulation during anaerobic fermentation of waste activated sludge. - Water Research 105: 209-217.

[2] Fang, H., Yu, H. Q. (2002): Mesophilic acidification of gelatinaceous wastewater. Journal of Biotechnology 93(2): 99-108.

[3] Forster-Carneiro, T., Perez, M., Romero, L. I. (2008): Influence of total solid and inoculum contents on performance of anaerobic reactors treating food waste. Bioresource Technology 99(15): 6994-7002.

[4] Garcia-Ochoa, F., Santos, V. E, Naval, L. et al. (1999): Kinetic model for anaerobic digestion of livestock manure. - Enzyme \& Microbial Technology 25(1): 55-60.

[5] Huang, Y., Zhao, M., Yang, L. et al. (2017): Study on methane production performance and kinetics of mixed kitchen digestion and excess sludge. - Journal of Food Science and Biotechnology 36(05): 486-93. 
[6] Jurado, E., Antonopoulou, G., Lyberatos, G. et al. (2016): Continuous anaerobic digestion of swine manure: ADM1-based modelling and effect of addition of swine manure fibers pretreated with aqueous ammonia soaking. - Applied Energy 172(190-8.

[7] Lauwers, J., Appels, L., Thompson, I. P. et al. (2013): Mathematical modelling of anaerobic digestion of biomass and waste: power and limitations. - Progress in Energy \& Combustion Science 39(4): 383-402.

[8] Linke, B. (2006): Kinetic study of thermophilic anaerobic digestion of solid wastes from potato processing. - Biomass and Bioenergy 30(10): 892-6.

[9] Liu, L., Xie, B., Ma, W. et al. (2017): Mixed soft measurement model of gas production by anaerobic treatment of wastewater based on kinetics and PSO-SVM. - China Papers 36(3): 31-6.

[10] Mata-Alvarez, J., Mac, S., Llabr, S. P. (2000): Anaerobic digestion of organic solid wastes. An overview of research achievements and perspectives. - Bioresource Technology 74(1): 3-16.

[11] Melikoglu, M., Webb, C. (2013): Analysing global food waste problem: pinpointing the facts and estimating the energy content. - Central European Journal of Engineering 3(2): $157-64$.

[12] Miao, H., Wang, S., Zhao, M. et al. (2014): Codigestion of Taihu blue algae with swine manure for biogas production. - Energy Conversion \& Management 77(1): 643-9.

[13] Pavan, P., Battistoni, P., Mata-Alvarez, J., Cecchi, F. (2000): Performance of thermophilic semi-dry anaerobic digestion process changing the feed biodegradability. Water Science \& Technology 41(3): 75-81.

[14] Pontes, R. F. F., Pinto, J. M. (2006): Analysis of integrated kinetic and flow models for anaerobic digesters. - Chemical Engineering Journal 122(1): 65-80.

[15] Rao, M. S., Singh, S. P. (2004): Bioenergy conversion studies of organic fraction of MSW: kinetic studies and gas yield-organic loading relationships for process optimisation. - Bioresource Technology 95(2): 173-85.

[16] Song, Y. C., Kwon, S. J., Woo, J. H. (2004): Mesophilic and thermophilic temperature co-phase anaerobic digestion compared with single-stage mesophilic- and thermophilic digestion of sewage sludge. - Water Research 38(7): 1653-62.

[17] Sun, Z., Zhang, J., Liu, Y. et al. (2016): Potential and kinetics of methane production by anaerobic digestion of cattle manure and corn stover. - Journal of Environmental Engineering 10(03): 1468-74.

[18] Syaichurrozi, I., Budiyono, Sumardiono, S. (2013): Predicting kinetic model of biogas production and biodegradability organic materials: Biogas production from vinasse at variation of COD/N ratio. - Bioresource Technology 149(2): 390.

[19] Vavilin, V. A., Fernandez, B., Palatsi, J. et al. (2008): Hydrolysis kinetics in anaerobic degradation of particulate organic material: an overview. - Waste Management 28(6): 939-51.

[20] Zeng, Y. (2017): Overview of the status quo of urban kitchen waste treatment. - Science and Technology Economics Guide (14): 9-10. 